\title{
Heparin-binding mechanism of the IGF2/IGF-binding protein 2 complex
}

\author{
Jacob Lund", Mads T Søndergaard ${ }^{*}$, Cheryl A Conover ${ }^{1}$ and Michael T Overgaard \\ Department of Biotechnology, Chemistry, and Environmental Engineering, Aalborg University, \\ Sohngaardsholmsvej 49, DK-9000 Aalborg, Denmark \\ 'Division of Endocrinology, Endocrine Research Unit, Mayo Clinic, Rochester, Minnesota, USA \\ *(J Lund and M T Søndergaard contributed equally to this work)
}

Correspondence should be addressed to $\mathrm{M}$ T Overgaard Email

mto@bio.aau.dk

\begin{abstract}
IGF1 and IGF2 are potent stimulators of diverse cellular activities such as differentiation and mitosis. Six IGF-binding proteins (IGFBP1-IGFBP6) are primary regulators of IGF half-life and receptor availability. Generally, the binding of IGFBPs inhibits IGF receptor activation. However, it has been shown that IGFBP2 in complex with IGF2 (IGF2/IGFBP2) stimulates osteoblast function in vitro and increases skeletal mass in vivo. IGF2 binding to IGFBP2 greatly increases the affinity for 2- or 3-carbon $\mathrm{O}$-sulfated glycosaminoglycans (GAGs), e.g. heparin and heparan sulfate, which is hypothesized to preferentially and specifically target the IGF2/IGFBP2 complex to the bone matrix. In order to obtain a more detailed understanding of the interactions between the IGF2/IGFBP2 complex and GAGs, we investigated heparin-binding properties of IGFBP2 and the IGF2/IGFBP2 complex in a quantitative manner. For this study, we mutated key positively charged residues within the two heparin-binding domains (HBDs) in IGFBP2 and in one potential HBD in IGF2. Using heparin affinity chromatography, we demonstrate that the two IGFBP2 HBDs contribute differentially to GAG binding in free IGFBP2 and the IGF2/IGFBP2 protein complex. Moreover, we identify a significant contribution from the HBD in IGF2 to the increased IGF2/IGFBP2 heparin affinity. Using molecular modeling, we present a novel model for the IGF2/IGFBP2 interaction with heparin where all three proposed HBDs constitute a positively charged and surface-exposed area that would serve to promote the increased heparin affinity of the complex compared with free intact IGFBP2.
\end{abstract}

Journal of Molecular Endocrinology (2014) 52, 345-355

\section{Introduction}

Insulin-like growth factor 1 (IGF1) and IGF2 are small polypeptides that have diverse autocrine, paracrine, and endocrine effects in various mammalian tissues (Clemmons 1997). A family of six high-affinity IGF-binding proteins (IGFBP1-IGFBP6) ensures the tight regulation of IGF half-life and the interaction with specific receptors (Bayes-Genis et al. 2000, Firth \& Baxter 2002, Forbes et al. 2012). The IGFBPs are homologs, structurally highly similar, and yet functionally very distinct. They all
Key Words

- IGF2/IGFBP2 complex

- glycosaminoglycans

- heparin affinity

- ternary binding model have similar $\mathrm{N}$ - and C-terminal domains that are connected by a variable linker region (Clemmons 2001, Bach et al. 2005, Forbes et al. 2012). The N- and C-terminal domains adopt distinct tertiary structures and both are required for high-affinity IGF binding, presumably in a cooperative fashion (Kuang et al. 2007). In vitro solution assays generally indicate that purified native or recombinant IGFBPs have a higher affinity for IGF peptides than do IGF receptors, making all six IGFBPs capable of binding 
IGFs and preventing receptor interaction and activation (Firth \& Baxter 2002, Denley et al. 2005). IGF2 exerts its action through the insulin receptor and the IGF receptor 1 (IGF1R) and is cleared from circulation by the IGF2R (Butler et al. 1998, Frasca et al. 1999, Bayes-Genis et al. 2000, Williams et al. 2007, Brown et al. 2008). In addition, certain IGFBPs have been shown to increase local IGF activity by targeting IGF and IGFBP complexes (IGF/IGFBP) to the cell membrane and the extracellular matrix (ECM) surrounding the cells (Conover 1992, Jones et al. 1993).

We had previously shown that IGFBP2 when complexed with IGF2 had increased binding to human osteoblast ECM while IGFBP2 alone and IGFBP2 in complex with IGF1 (IGF1/IGFBP2) showed little or no binding (Khosla et al. 1998, Conover \& Khosla 2003). IGFBP2 was unique among the six IGFBPs in exhibiting IGF2-enhanced matrix binding (Conover \& Khosla 2003). Similarly, Arai et al. (1996) demonstrated that IGF/IGFBP2 complexes were able to bind heparin-sepharose and ECM produced by human fibroblasts. These investigators further suggested that binding of IGF/IGFBP2 was principally to heparin-like glycosaminoglycans (GAGs). Our results indicated that heparin, heparan sulfate, and high salt inhibited IGF2-enhanced IGFBP2 binding to human osteoblast ECM while chondroitin sulfate, integrins, and mannitol did not. These observations further supported binding to highly sulfated GAGs particularly abundant in bone (Conover \& Khosla 2003). Moreover, in a matrix-rich environment, the IGF2/IGFBP2 complex was as effective as IGF2 alone in stimulating osteoblast proliferation, whereas IGFBP2 alone had no effect (Conover 2008). The mechanism for this IGF2/IGFBP2 stimulation of osteoblastic cell receptors is unclear. No evidence of proteolytic cleavage and no apparent change in IGFBP2 affinity for IGF with matrix association were observed (Conover \& Khosla 2003). This is in contrast to IGFBP3 and IGFBP5 binding to cell surface and matrix, respectively, which results in reduced affinity for IGFs, thus potentially releasing the growth factors (Clemmons 2001).

IGFBP2 contains two heparin-binding domains (HBDs), one in the C-terminal domain and the other located in the linker region (Hodgkinson et al. 1994, Russo et al. 2005, Kuang et al. 2006). In addition, IGF2 possesses a putative HBD that is not present in IGF1 (Cardin \& Weintraub 1989, Conover \& Khosla 2003). The aim of this study was to investigate heparin-binding properties of the IGF2/IGFBP2 complex and evaluate these at the structural level. To this end, we employed an Escherichia coli-based co-expression system to produce a panel of murine $I g f b p 2$ variants in complex with human IGF2, with mutations of key positively charged HBD residues. The heparin-binding properties of these IGF2/IGFBP2 complexes were then determined using heparin affinity chromatography as a surrogate model for bone ECM GAGs. In conjunction with structural modeling, the results lead us to propose a new model for the ternary IGF2/IGFBP2/heparin interaction.

\section{Subjects and methods}

\section{Generation of expression plasmids}

DNA encoding two fusion proteins were cloned into a pETDuet 1 plasmid (Merck, Darmstadt, Germany): i) human IGF2 with an N-terminal thioredoxin, spaced by six His residues and a tobacco etch virus (TEV) protease recognition site and ii) murine IGFBP2 with an N-terminal maltose-binding protein, spaced by a TEV protease recognition site and a sixGly linker. Site-directed mutagenesis of the co-expression vector was used to generate IGF2 and IGFBP2 mutations. Selected Lys, Arg, or His residues were changed to Ala using the Quikchange Lightning Site-Directed Mutagenesis Kit (Agilent Technologies, Santa Clara, CA, USA) according to the manufacturer's protocol. Reverse complementary sets of mutagenesis primers were purchased from TAG Copenhagen (Copenhagen, Denmark). Forward primer sequences: linker-HBD (IGFBP2 K162A K163A, 5'-CTCAGTCTGGAGGAGCCCGCAGCGCTGCGCCCGCCTCCCGCCAGGACC-3'), C-term-HBD (IGFBP2 K209A H210A K216A，5'-CCCCAACTGTGACGCCGCGGGCCGGTACAACCTTGCGCAGTGCAAGATGTCTCTGAACGG-3'), IGF2 HBD (IGF2 R37A R38A R40A, 5'-CGCAAGCCGTGTGAGCGCTGCTAGCGCTGGCATCGTTGAGGAGTG-3'), and IGFBP2 control mutation (R188A R193A, 5'-GGATCTCCACCATGGCTCTTCCGGATGATGCTGGCCCCCTGG-3'). The resulting plasmids were verified by sequencing (Eurofins, Luxembourg, Luxembourg).

\section{Protein expression}

Fusion proteins were co-expressed in E. coli Rosetta-gami B (DE3) (Novagen) using buffered LB medium (10 g/l $\mathrm{NaCl}, 10 \mathrm{~g} / \mathrm{l}$ tryptone, $5 \mathrm{~g} / \mathrm{l}$ yeast extract, $10 \mathrm{~g} / \mathrm{l}$ D-glucose, $1.5 \mathrm{~g} / 1 \mathrm{KH}_{2} \mathrm{PO}_{4}$, and $10 \mathrm{~g} / 1 \mathrm{~K}_{2} \mathrm{HPO}_{4}$, added with $100 \mathrm{mg} / \mathrm{l}$ ampicillin and $34 \mathrm{mg} / \mathrm{l}$ chloramphenicol) at $\mathrm{pH} 7$. Cultures were grown at $37^{\circ} \mathrm{C}$ to $\mathrm{OD}_{600 \mathrm{~nm}} \sim 1$ in an aerated 21 bioreactor (Sartorius BBI Systems, Melsungen, Germany) with $\mathrm{pH}$ regulation before induction with $0.5 \mathrm{mM}$ isopropyl B-D-1-thiogalactopyranoside (IPTG). Protein expression was continued at $25^{\circ} \mathrm{C}$ for $19 \mathrm{~h}$ before harvest by centrifugation at $4000 \boldsymbol{g}$ and $4{ }^{\circ} \mathrm{C}$ for

Published by Bioscientifica Ltd. 
$30 \mathrm{~min}$. Cells were resuspended in lysis buffer $(20 \mathrm{mM}$ Tris, $50 \mathrm{mM} \mathrm{NaCl}, 5 \mathrm{mM}$ imidazole, $2 \mathrm{mM} \mathrm{MgSO}_{4}, 1 \mathrm{mM}$ $\beta$-mercaptoethanol, $1 \mathrm{~g} / 1$ lysozyme, $25 \mathrm{U} / \mathrm{ml}$ benzonase, and $0.5 \%$ (volume/volume) protease inhibitor cocktail III (Merck), pH 7.5) and lysed by repeated freeze-thaw cycles. Cell debris was removed by centrifugation at $90000 \boldsymbol{g}$ for $45 \min$ at $4{ }^{\circ} \mathrm{C}$.

\section{Protein purification}

The complexes of IGF2 and IGFBP2 fusion proteins were purified by immobilized metal ion affinity chromatography using a Ni-NTA column (Qiagen). IGF2/IGFBP2 fusion proteins containing fractions were dialyzed against a TEV compatible buffer $(20 \mathrm{mM}$ Tris, $2 \mathrm{mM}$ 2-mercaptoethanol, $1 \mathrm{mM}$ EDTA, and 1\% glycerol, $\mathrm{pH} 8$ ) and $5 \mu \mathrm{g} / \mathrm{ml}$ added recombinant, modified TEV protease (Kapust et al. 2001). Liberated IGF2/IGFBP2 complexes were further purified by cation-exchange chromatography using a Source $15 \mathrm{~S}$ resin (GE Healthcare, Little Chalfont, Bucks, UK) at $\mathrm{pH}$ 6.5. Finally, the purified IGF2/IGFBP2 preparations were buffer exchanged using a Fast Desalting HR 10/10 column (GE Healthcare) into buffers containing $20 \mathrm{mM}$ acetate, $20 \mathrm{mM}$ MES or $20 \mathrm{mM}$ phosphate, and $50 \mathrm{mM} \mathrm{NaCl}$ at pH $5.5,6.5$, or 7.5 respectively. To obtain free IGFBP2, the individual protein complexes were separated by size-exclusion chromatography (Superdex 75 HR 10/30 (GE Healthcare)) at pH 3 (50 mM citrate and 20\% (v/v) acetonitrile) followed by buffer exchange as described previously. Human IGFBP3 and IGF1/IGFBP3 complex were kind gifts from Andreas Sommer (Insmed, Bridgewater, NJ, USA), and human IGFBP4 and IGF2/IGFBP4 complex were essentially cloned, expressed, and purified as described above (M T Overgaard, in preparation).

\section{Protein analysis}

Purified proteins were analyzed by SDS-PAGE in presence or absence of $50 \mathrm{mM}$ dithiothreitol (DTT) and stained with Coomassie brilliant blue G250. Secondary structure of protein was assayed using circular dichroism (CD) on a Chirascan Plus spectropolarimeter (Applied Photophysics, Leatherhead, Surrey, UK). CD spectra of $200 \mu \mathrm{g} / \mathrm{ml}$ protein complexes in acetate buffer at $\mathrm{pH} 5.5$ were acquired in the range of $195-260 \mathrm{~nm}$ at $25^{\circ} \mathrm{C}$ using a $0.5 \mathrm{~mm}$ light-path cuvette. CD measurements were subtracted from buffer scan, baseline corrected, adjusted for CD signal intensity using the absorbance signal measurements, and converted to corrected mean residue weighted molar ellipticity $\left(\theta^{*}{ }_{\mathrm{MRW}}\left(\mathrm{dg} \times \mathrm{m}^{2} / \mathrm{dmol}\right)\right)$. Protein identity was confirmed by peptide mass fingerprinting using MALDI-TOF mass spectrometry of tryptic peptides on a Bruker Reflex III. To investigate the protein disulfide bridge pattern, alkylated samples $(100 \mathrm{mM}$ iodoacetic acid for $0.5 \mathrm{~h}$ ), with or without prior DTT reduction, were similarly digested with trypsin and analyzed by MALDI-TOF MS.

\section{Heparin affinity chromatography}

Relative heparin affinities of protein complexes and IGFBPs alone were analyzed using heparin affinity chromatography at various $\mathrm{pH}$ values. A fast protein liquid chromatography system (ÄKTApurifier 10, GE Healthcare) equipped with a $1 \mathrm{ml}$ HiTrap Heparin HP column (GE Healthcare), u.v.-280 nm absorption (UV-900, GE Healthcare), and a conductivity detector (pH/C-900, GE Healthcare) was used at a flow rate of $1 \mathrm{ml} / \mathrm{min}$. Heparin affinity was assayed in $20 \mathrm{mM}$ acetate, $\mathrm{pH} 5.5$, and $50 \mathrm{mM}$ $\mathrm{NaCl}$ for all experiments, except for the experiments with varying $\mathrm{pH}$, where $20 \mathrm{mM}$ MES or $20 \mathrm{mM}$ phosphate, and $50 \mathrm{mM} \mathrm{NaCl}$ at $\mathrm{pH} 6.5$ or 7.5 , respectively, were employed. The ionic strength - measured as the retention conductance $\left(\kappa_{\mathrm{r}}(\mathrm{mS} / \mathrm{cm})\right)$ - necessary to elute the bound proteins was a measure of relative heparin affinity. Triplicate measurements of $\kappa_{\mathrm{r}}$ for IGFBP2 variants with and without IGF2 were subjected to a two-way ANOVA with the Bonferroni's pairwise comparison test of all possible

\begin{tabular}{|l|l|l|}
\hline Complex & IGF2 & IGFBP2 \\
\hline IGF2/IGFBP2 & WT & Cartoon \\
\hline IGF2/IGFBP2_linker-HBD & WT & $\begin{array}{l}\text { K162A } \\
\text { K163A }\end{array}$ \\
\hline IGF2/IGFBP2_C-term-HBD & WT & $\begin{array}{l}\text { K209A } \\
\text { H210A } \\
\text { K216A }\end{array}$ \\
\hline IGF2 HBD/IGFBP2 & $\begin{array}{l}\text { R37A } \\
\text { R38A } \\
\text { R40A }\end{array}$ & WT \\
\hline IGF2/IGFBP2_Ctrl & WT & $\begin{array}{l}\text { R188A } \\
\text { R193A }\end{array}$ \\
\hline
\end{tabular}

Figure 1

Overview of protein complexes investigated. The first column shows the nomenclature used throughout the text. The second and third columns illustrate the specific mutations introduced in IGF2 or IGFBP2 respectively. The numbering refers to the sequences of mature human IGF2 and murine IGFBP2 respectively (Fig. 2). The fourth column shows cartoons of the individual complexes, which will be used to aid nomenclature. IGFBP2 ( $\mathrm{N}$-terminal domain, blue; linker region, white; and C-terminal domain, green), IGF2 (red), and mutations (black circles).

Published by Bioscientifica Ltd. 
combinations with a mutational variant and IGF2-binding state as independent variables (GraphPad Software, Prism 5, La Jolla, CA, USA). The triplicate measurements of $\kappa_{\mathrm{r}}$ for the binary complexes at various $\mathrm{pH}$ levels were analyzed in an equivalent analysis with $\mathrm{pH}$ and protein variants as independent variables.

\section{Homology structural modeling}

MODELLER v.9.10 was used for the generation of a threedimensional structural model of the IGF2/IGFBP2 complex using the structures of human IGF1 in complex with human IGFBP4 N- and C-terminal domains (PDB ID: 2DSR), C-terminal domain of human IGFBP2 (PDB ID: 2H7T), and IGF2 (PDB ID: 1IGL) as templates (Torres et al. 1995, Eswar et al. 2006, Kuang et al. 2006, Sitar et al. 2006). Clustal W sequence alignments of template sequences, and murine IGFBP2 (ID P47877) and human IGF2 (ID P01344), respectively, were used to generate 50 models. The bestranked model was further refined using the MODELLER loop refinement algorithm. Stereochemical quality of the generated models was inspected using the SAVES server (http://nihserver.mbi.ucla.edu/SAVES/), where the final model passed three-dimensional benchmarking with Verify_3D as well as being in agreement with allowed Ramachandran conformations (Eisenberg et al. 1997).

\section{Results}

\section{Protein expression, purification, and analysis}

Four different IGF2/IGFBP2 variants were made by exchanging positively charged residues in putative HBDs to Ala, three involving mutations IGFBP2 (linker-HBD, C-terminal domain HBD, and a control variant) and one with mutations in the proposed IGF2 HBD (Figs 1 and 2). Rosetta-gami (DE3) cells, which have a favorable cytosolic environment for disulfide formation, were used for co-expression of murine IGFBP2 and human IGF2, both as fusion proteins. The first step of the purification employed $\mathrm{Ni}^{2+}$ affinity selectively binding IGF2 fusion proteins (which include a hexa-histidine sequence), and thereby simultaneous co-purification of IGFBP2 fusion proteins capable of forming a complex with IGF2. The following specific proteolytic cleavage with TEV protease, subsequent cation exchange, and size-exclusion chromatography steps ensured removal of non-complexed IGF2, released fusion protein affinity tags, non-cleaved fusion proteins, and TEV protease. Denaturing SDS-PAGE analysis of the purified complexes demonstrated identical electrophoretic mobility for all variants of IGFBP2 both under reducing and non-reducing conditions respectively (Fig. 3A). The IGFBP2 variants all displayed an identical small decrease in electrophoretic mobility under reducing conditions, supporting the presence of an intact disulfide bond pattern - further analyzed below. IGF2 HBD variant displayed a slightly increased mobility relative to IGF2, consistent with the substitution of three positively charged Arg residues for Ala. CD was used to probe for potential structural differences between the IGF2/IGFBP2 variants (Fig. 3B). The CD spectra were highly similar for all complexes, indicating no significant differences in the secondary structure content of protein.

MALDI-TOF analysis of tryptic peptides generated from reduced samples confirmed the introduction of

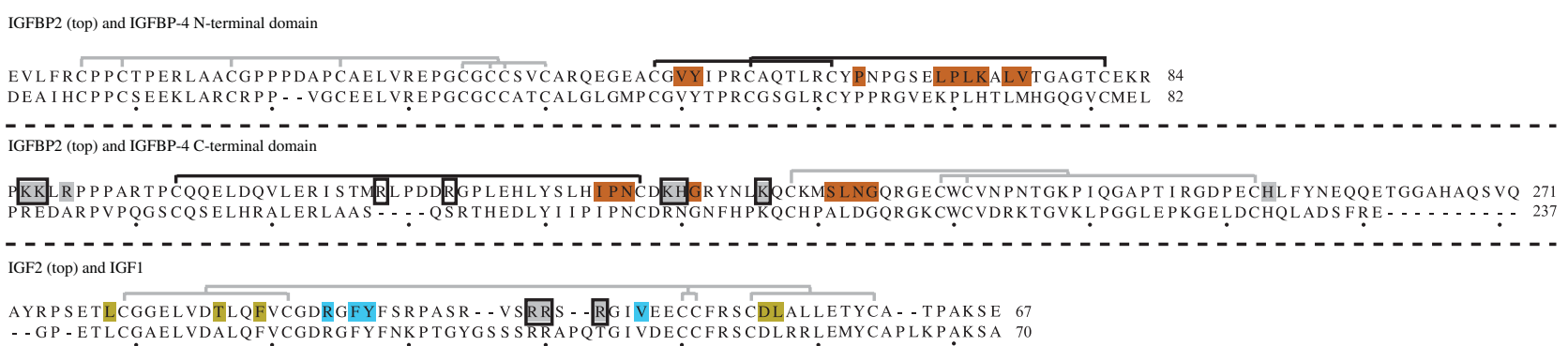

\section{Figure 2}

Amino acid sequence alignments for homology modeling with annotations added. (Upper and middle panels) Sequences for the N-terminal domain (Glu1-Arg84) and C-terminal domain (Arg170-GIn271 plus adjacent linker region residues Pro161-Ala169) from mature murine IGFBP2 aligned with the corresponding parts of mature human IGFBP4. (Lower panel) Mature human IGF2 is aligned with human IGF1. IGFBP2 linker (Lys162-Arg165) and C-terminal domain (Lys209-His210, Lys216, and His253) HBD residues are colored in gray along with the proposed IGF2 HBD residues (Arg37-Arg40).
The charged residues mutated to Ala in this study are boxed. IGF2-binding residues of IGFBP2 are highlighted in orange. IGF2 residues involved in IGF1R (turquoise) and IGF2R (olive green) binding are also highlighted (Butler et al. 1998, Clemmons 2001, Kuang et al. 2006, Williams et al. 2007, Brown et al. 2008). Disulfide bridges identified in this study are shown with black lines. Identified disulfide clusters are shown with gray lines. Numbering corresponds to mature murine IGFBP2 and human IGFBP4, IGF1, and IGF2 as indicated. 
mutations (data not shown). Analysis of iodoacetic acidtreated, non-reduced proteins showed no alkylation of any Cys-containing peptides, strongly indicating that no free Cys-SH was present (data not shown). Furthermore, tryptic peptide mass fingerprinting of non-reduced protein complexes identified Cys-Cys crosslinked peptides consistent with the previously reported IGFBP disulfide structures for the N-terminal domain of IGFBP4 and IGFBP5 and the C-terminal domain of IGFBP2 (and other IGFBPs; Smith et al. 1989, Kalus et al. 1998, Zesławski et al. 2001, Mark et al. 2005, Siwanowicz et al. 2005, Sitar et al. 2006, Brown et al. 2008, Nili et al. 2012). This pattern can be described by numbering the Cys residues consecutively. The N-terminal domain Cys-Cys linkages are C1-C5, C2C6, C3-C7, C4-C8 (forming a cluster of three crosslinked tryptic peptides), C9-C11, and C10-C12. The C-terminal
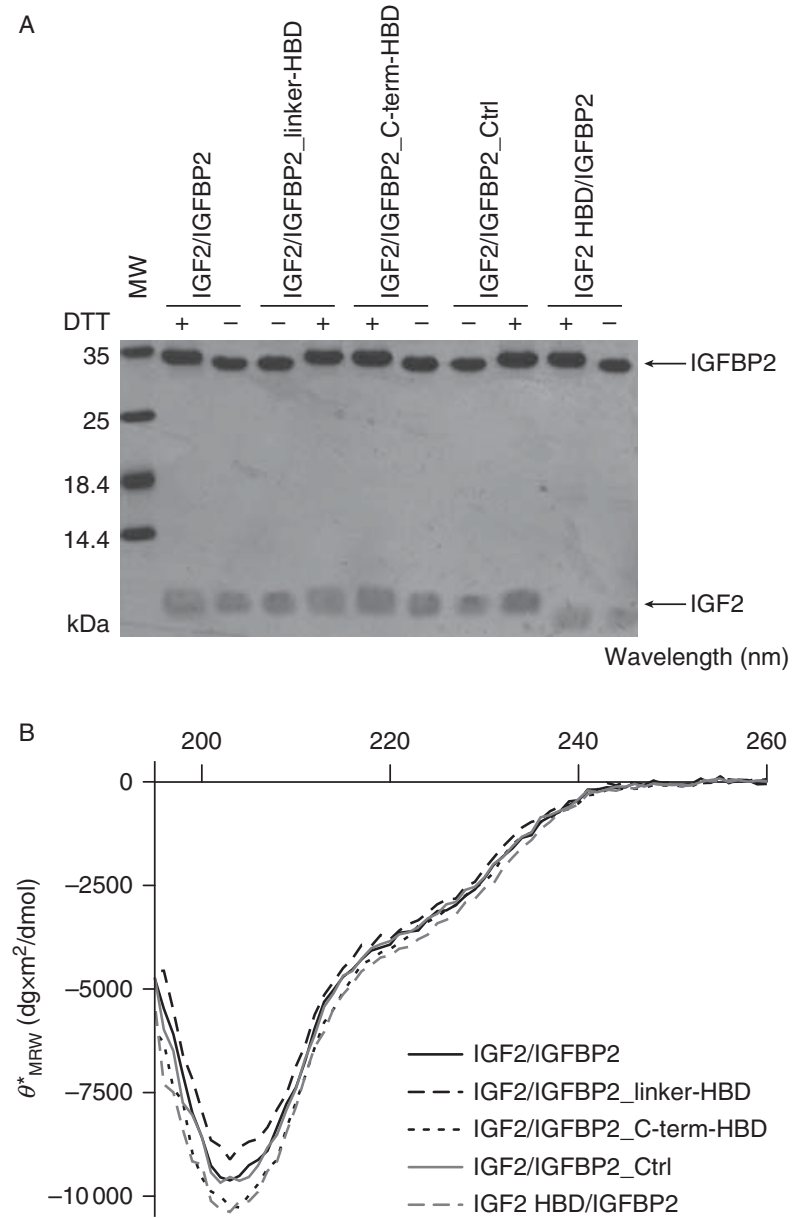

Figure 3

Analysis of protein-folding integrity. (A) SDS-PAGE analysis of the purified protein complexes. (B) Far-u.v. CD spectra of protein complexes in acetate buffer at $\mathrm{pH} 5.5$ and $25^{\circ} \mathrm{C} . \theta^{*} \mathrm{MRW}$ is the corrected mean residue weight ellipticity.

http://jme.endocrinology-journals.org DOI: 10.1530/JME-13-0184

C) 2014 Society for Endocrinology Printed in Great Britain domain linkages are C13-C14, C15-C16, and C17-C18 disulfides, the latter two being expected to result in a threepeptide cluster upon tryptic digestion. In addition, the IGF2 disulfide connections (C1-C4, C2-6, and C3-C5) are expected to connect three tryptic peptides in one cluster.

We specifically verified the IGFBP2 C9-C11 and C10C12 linkages (Cys48-Cys61 and Cys55-Cys81, respectively, using mature murine IGFBP2 sequence numbering) in the N-terminal domain, and the C13-C14 (Cys173Cys207) disulfide in the C-terminal domain (Fig. 2). Further delineation of the disulfide patterns was impaired by the close proximity of the Cys residues. However, the expected peptide clusters from tryptic digest of IGFBP2 and IGF2 were identified (Fig. 2). Importantly, this observation was consistent for all IGF2/IGFBP2 variants.

\section{Heparin affinity chromatography}

The relative heparin-binding strength of the IGF2/IGFBP2 complex, free IGFBP2, and variants was analyzed by heparin affinity chromatography with the retention conductances $\left(\kappa_{\mathrm{r}}(\mathrm{mS} / \mathrm{cm})\right)$ taken as a measure of their respective heparin affinities. Free IGFBP2 and complexes were eluted in single peaks as detected by u.v. absorption (examples of IGF2/IGFBP2 elution from the heparin column are shown in Supplementary Figure 1, see section on supplementary data given at the end of this article).

Initially, the protein complexes were investigated (Fig. 4). The retention conductance, $\kappa_{\mathrm{r}}$, was determined as the conductivity at the chromatographic elution peak. Mutations of positively charged HBD residues to Ala generally decreased IGF2/IGFBP2 heparin affinities, as seen by elution at a lower $\kappa_{\mathrm{r}}$. However, the specific disruption of HBDs affected the heparin affinity of the complexes to different extents, with the general order of affinities being IGF2/IGFBP2 $=$ IGF2/IGFBP2_Ctrl $>$ IGF2/IGFBP2 C-term-HBD > IGF2/IGFBP2_linker-HBD > IGF2 HBD/IGFBP2. The observed differences were all statistically significant $(P<0.01)$. These observations demonstrated differential contributions of the individual HBDs. The IGFBP2 C-terminal domain HBD contributed less than the linker-HBD to the IGF2/IGFBP2 heparin affinity. Further, the proposed IGF2 HBD contributed significantly more than the two IGFBP2 HBDs to the IGF2/IGFBP2 complex heparin affinity. As a method of validation and a point of reference, the human IGF1/IGFBP3 and human IGF2/IGFBP4 complexes were also analyzed as these were previously shown to exhibit strong and no significant GAG binding respectively. The IGF1/IGFBP3 complex bound to the heparin column with a higher affinity than

Published by Bioscientifica Ltd 


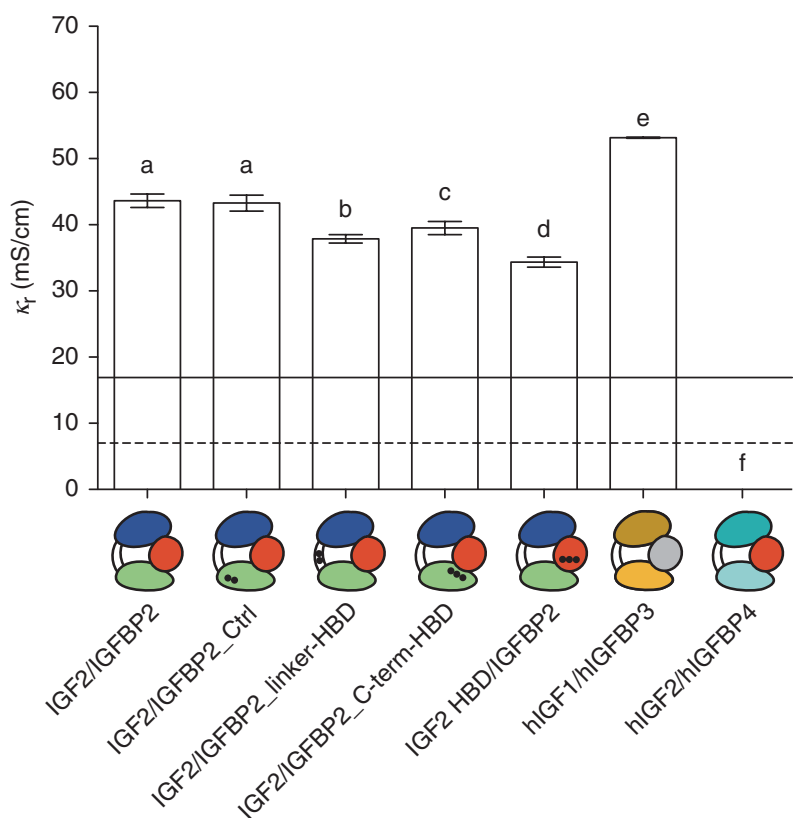

Figure 4

Heparin affinities of IGF/IGFBP complexes. Columns indicate mean and bars the S.D. of triplicates at $\mathrm{pH}$ 5.5. Lettering indicates statistically unique values as determined from two-way ANOVA with pairwise comparisons $(P<0.01)$. IGF2/IGFBP4 did not bind to the column at the applied loading conditions $\left(\kappa_{\mathrm{r}} \sim 8 \mathrm{mS} / \mathrm{cm}\right)$. Cartoons are added to aid the nomenclature with IGFBP3 $\mathrm{N}$ - and C-terminal domains in brown and orange respectively. IGFBP4 $\mathrm{N}$ - and C-terminal domains are in sea green and turquoise color, respectively, also IGF1 is in gray color. See Fig. 1 for additional color legend. Lines indicate $\kappa_{\mathrm{r}}$ for loading conditions (dotted) and PBS (solid).

the IGF2/IGFBP2 complex, while the IGF2/IGFBP4 complex showed no measurable heparin binding at the column loading conditions. Mutation of surface exposed, charged residues not part of any proposed HBD (IGF2/IGFBP2_Ctrl) resulted in a heparin-binding affinity indistinguishable from that of the WT IGF2/IGFBP2 complex and thus confirmed that the protein complex interaction with the heparin column was governed by specific interactions and not overall charges, i.e. true affinity chromatography and not ion-exchange chromatography. In support of this was also the ion-exchange capacity of the applied HiTrap Heparin column which was $\sim 25$-fold less than that of the Source 15S column used during purification, and the protein complexes displayed an 2.3-fold greater affinity for the HiTrap Heparin column compared with the Source $15 \mathrm{~S}$ column as measured by $\kappa_{\mathrm{r}}$ (data not shown).

Then, we investigated the significance of the individual IGFBP2 HBDs in the free IGFBP2 variants by the same method (Fig. 5). Both HBD-targeted variants displayed a decreased heparin affinity, demonstrating that both HBDs are needed for maintaining the heparin affinity of free IGFBP2. The control variant, IGFBP2_Ctrl, displayed the same affinity as the WT IGFBP2. Interestingly, the order of affinities was IGFBP2 $>$ IGFBP2_linker-HBD > IGFBP2_ C-term-HBD implying a reversed significance of the two HBDs in free IGFBP2 relative to the IGF2/IGFBP2 complex. Again, all observed differences were statistically significant $(P<0.01)$. In case of free IGFBP2, the C-terminal domain HBD appeared to contribute significantly more to the overall heparin affinity than the linker-HBD. This result also implied that different IGFBP2 HBDs might be relevant for targeted GAG binding of the free IGFBP2 and IGF2/IGFBP2 complex respectively. Finally, free IGFBP2 showed significantly (all $P<0.01$ ) decreased heparin affinity relative to their respective complexes with IGF2, and this was consistent across WT, control, and mutated proteins (compare Figs 4 and 5).

The relative impact of the IGF2 HBD mutation was surprising, why free IGFBP2, IGF2/IGFBP2, and IGF2 HBD/IGFBP2 mutated complex were compared separately (Fig. 6). In general, binding of IGF2 increases the heparin affinity of IGFBP2. However, binding of IGF2 with a dysfunctional HBD resulted in a significantly decreased affinity compared with the free IGFBP2. As the C-terminal

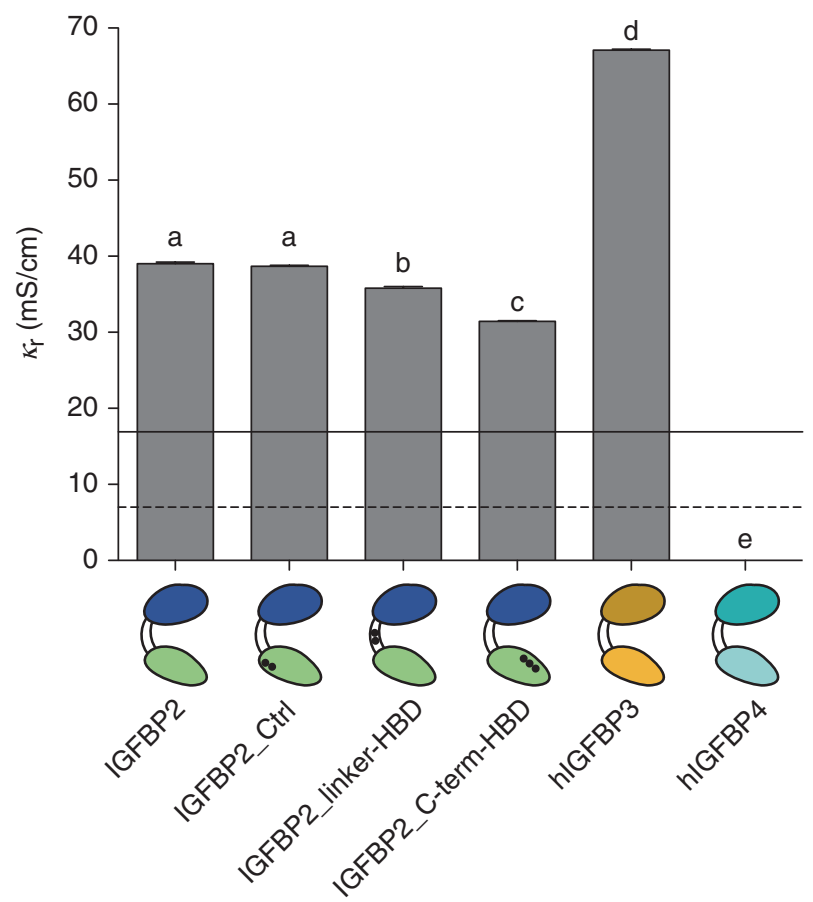

\section{Figure 5}

Heparin affinities of free IGFBPs. Information in graph is the same as described for Fig. 4. Lettering indicates statistically unique values as determined from two-way ANOVA with pairwise comparisons $(P<0.01)$.

Published by Bioscientifica Ltc. 


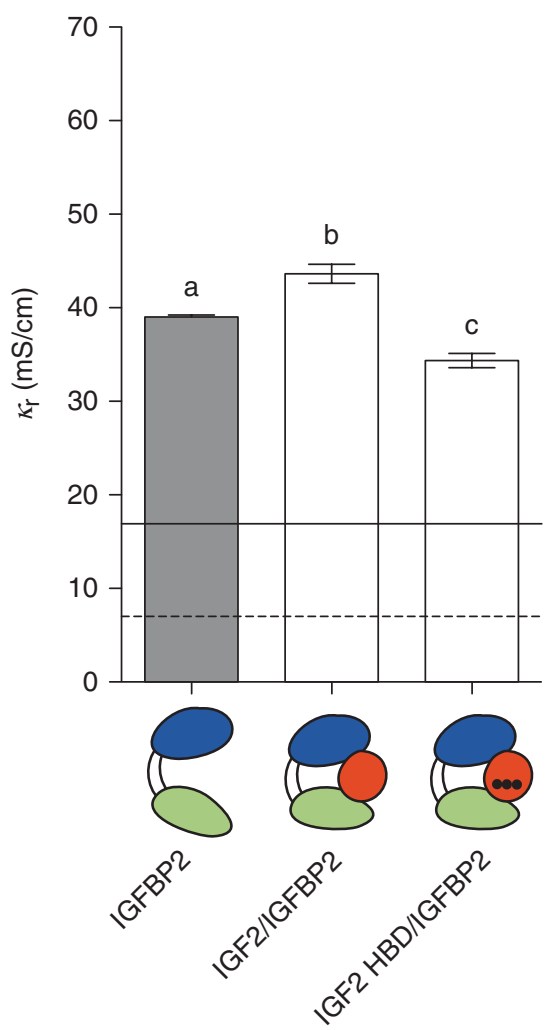

Figure 6

Heparin affinities of IGFBP2, IGF2/IGFBP2, and IGF2 HBD mutated complex. Information in the graph is the same as described for Fig. 4. Lettering indicates statistically unique values as determined from two-way ANOVA with pairwise comparisons $(P<0.001)$.

HBD of IGFBP2 contributes less to the overall heparin affinity of the complex than it does for the free binding protein, IGF2 binding appears to partly mask the IGFBP2 C-terminal domain HBD. This would further enforce the importance of the IGF2 HBD in the increased heparin affinity demonstrated by the complex compared with free IGFBP2.

\section{The $\mathrm{pH}$ dependency of IGF2/IGFBP2 heparin affinity}

Bone ECM shows local $\mathrm{pH}$ gradients during remodeling and these could be part of IGF2/IGFBP2 targeting to this tissue (Arnett 2003). To further investigate this hypothesis, heparin affinities of the IGF2/IGFBP2 variants were measured at different $\mathrm{pH}$ levels. The results demonstrated decreased heparin affinity with increasing $\mathrm{pH}$ (Fig. 7). Most complexes displayed a similar $\mathrm{pH}$ dependency in the range of $\mathrm{pH} 5.5-7.5$, as indicated by the parallel courses of their heparin affinities as a function of $\mathrm{pH}$. The IGF2/IGFBP2_C-term-HBD was an exception demonstrating a slightly lower $\mathrm{pH}$ dependency. As the His210 residue was mutated to Ala in the IGF2/IGFBP2 C-term-HBD, this observation supported that His 210 was involved in the heparin interactions of the other complexes and that this residue changes its protonation state in the $\mathrm{pH}$ interval of 5.5-7.5. Furthermore, the residual $\mathrm{pH}$ dependence of the IGF2/IGFBP2_C-term-HBD complex implied that at least one other His residue contributes to the IGF2/IGFBP2 heparin affinity. This was most likely His253, which has been demonstrated to be part of the HBD of the isolated IGFBP2 C-terminal domain (Kuang et al. 2006). All observed differences, i.e. between protein variants and $\mathrm{pH}$ levels, were statistically significant (all $P<0.001$ ).

\section{Structural modeling of IGF2/IGFBP2}

Homology modeling based on the structure of human IGF1 complexed to the N- and C-terminal domains of IGFBP4 was used to create a structural model of the IGF2/IGFBP2 complex (Fig. 8). The sequence alignment input is shown in Fig. 2. The C-terminal eight residues of the linker domain (Pro161-Ala169) of IGFBP2 (covering the linker-HBD) were included in the model to illustrate the proximity to the C-terminal domain start. Noteworthy, the C-chain of IGF1, including the residues aligning to the IGF2 HBD, is not resolved in the template structure, indicating a high

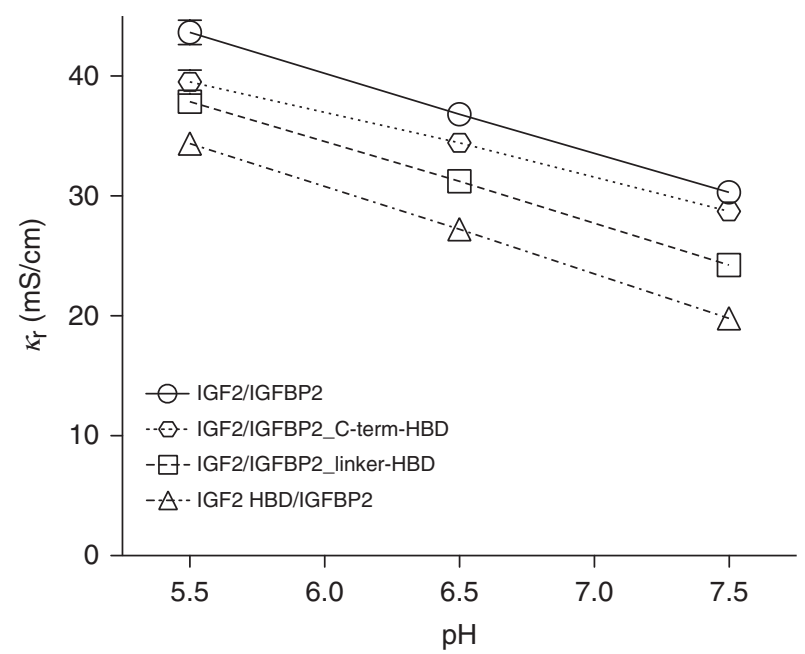

Figure 7

Heparin affinities of IGF2/IGFBP2 variants as a function of $\mathrm{pH}$. Note that the IGF2/IGFBP_C-term-HBD lacked His209 and demonstrated reduced pH sensitivity. Notations are as given in Fig. 1. Connecting lines drawn to guide the eye. Error bars indicate s.D. (in most cases smaller than the symbol sizes). All values were statistically significant and different from each other as determined from two-way ANOVA with pairwise comparisons $(P<0.001)$.

Published by Bioscientifica Ltd 
flexibility of this loop. However, adjacent residues are clearly defined and support the homology model as a good estimate for the position of the IGF2 HBD (see Subjects and methods). The IGF2/IGFBP2 structural model served to tentatively evaluate the HBDs and IGF2-binding site properties. All residues predicted to be involved in heparin binding (gray) were surface exposed in the homology model, including the proposed IGF2 HBD (Fig. 8B). Interestingly, the three HBDs together form an elongated positively charged surface consisting of the IGF2 HBD flanked by the IGFBP2 linker and C-terminal domain HBDs on either side (Fig. 8B and C). A heparin molecule or equivalent GAG polymer may be thought to wrap around the complex across the IGFBP2 C-terminal domain, IGF2, and the IGFBP2 linker-HBDs and bind via electrostatic interactions with the exposed positive charges (Fig. 8C). The IGFBP2 C-terminal domain HBD Lys209 and His210 were in close proximity to the IGF2-binding surface with the possibility of especially Lys209 being partly buried by IGF2, albeit still somewhat surface exposed. This may potentially explain the decreased heparin binding of the IGF2 HBD/IGFBP2 complex compared with free IGFBP2, as hypothesized above (Fig. 6).

IGFBP2 residues previously identified to be involved in IGF2 binding (orange) were consistently found buried in the interface between IGFBP2 and IGF2 or the interface of the two IGFBP2 domains (Fig. 8A). IGF2 residues involved in IGF1R and IGF2R binding (Arg24/Phe26/Tyr27/Val43 (turquoise) and Leu8/Thr16/Phe19/Asp56/Leu53 (olive green) respectively) were partly buried by the IGFBP2 domains (Figs 2 and 8). Only two of four IGF1R-binding residues in IGF2 (Tyr27/Arg24 (turquoise)) were partially surface exposed in the IGF2/IGFBP2 model. It was noteworthy that the IGF2 IGF1R-binding residues were positioned away from the IGF2 HBD in the modeled IGF2 structure (Fig. 8B). Similarly, only two of the five
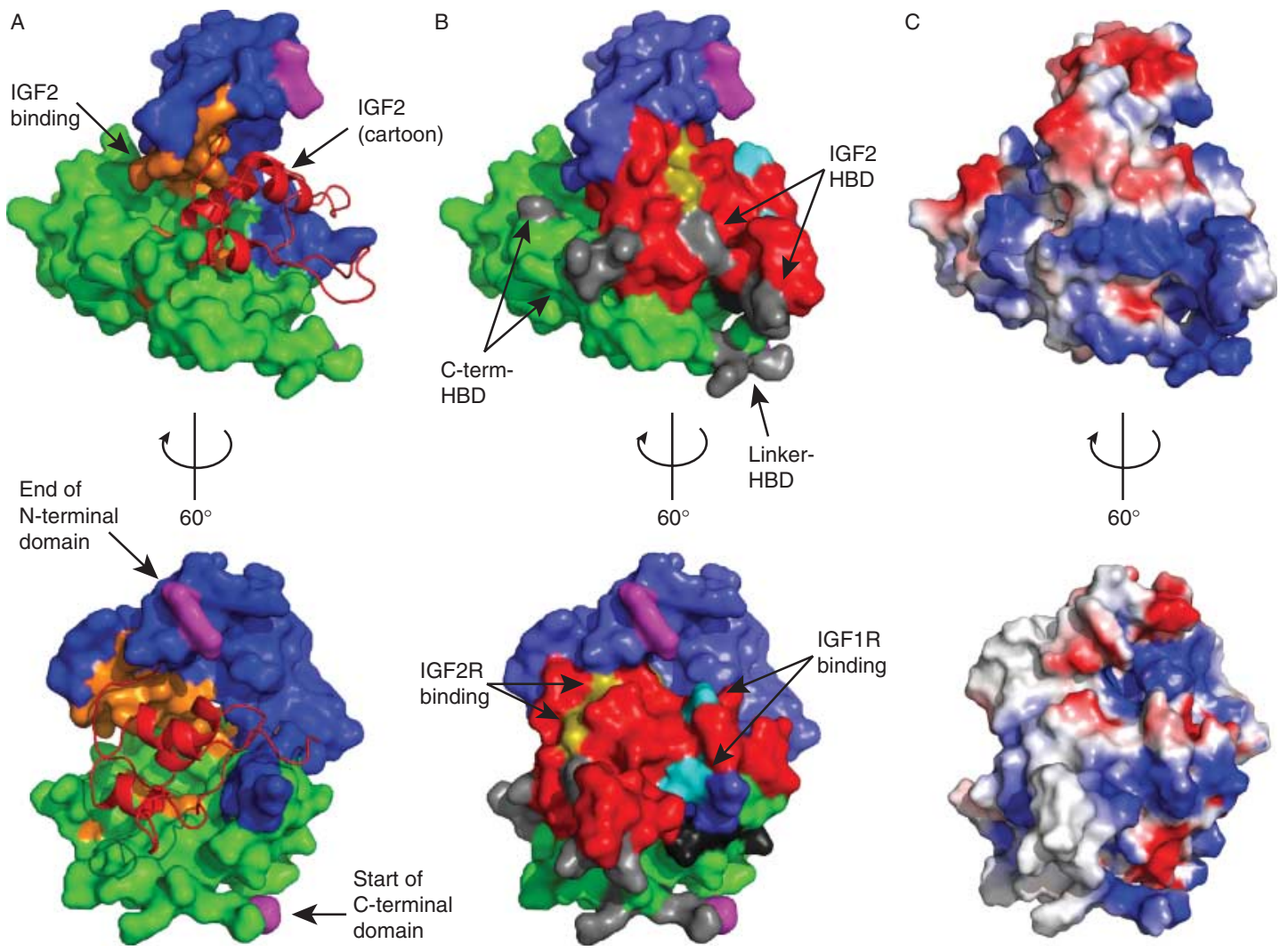

\section{Figure 8}

Three-dimensional, structural model of the IGF2/IGFBP2 complex based on homology modeling to the human IGF1/IGFBP4 complex. (A and B) Surface rendered model ((A) IGF2 shown as cartoons), highlighting the different features of the complex. IGFBP2 N- and C-terminal (including linker domain residues Pro161-Ala169) domains (blue and green respectively), IGF2-binding residues (orange), IGF2 (red), HBD residues (gray),
IGF1R-binding residues (turquoise) and IGF2R-binding residues (olive green), attachment points for the linker region (purple), and control mutations (black). (C) Surface rendering with charge plot. The modeled IGFBP2 N-terminal domain is in good agreement with the one presented by Galea et al. (2012). http://jme.endocrinology-journals.org DOI: 10.1530/JME-13-0184
(๑) 2014 Society for Endocrinology Printed in Great Britain 
IGF2R-binding residues in IGF2 (Asp52/Leu53 (olive green)) were surface exposed in the model, and furthermore, these residues were adjacent to the suggested IGF2/IGFBP2 combined heparin-binding surface. The latter could be indicative of IGF2/IGFBP2 heparin binding further burying IGF2 residues interacting with IGF2R. The model was validated through spatial and energy calculations as detailed above, and furthermore, the IGFBP2 N-terminal domain was in good agreement with a recently published homology model (Galea et al. 2012). In addition, the disulfide bridges identified by peptide mass fingerprinting were consistent with those of the model (not highlighted).

\section{Discussion}

In this study, we employed site-directed mutagenesis, affinity chromatography, and structural modeling to determine heparin-binding interactions of full-length IGFBP2 in presence and absence of IGF2. We found that the two HBDs in IGFBP2 contribute differentially depending on IGF2 binding, while the previously uncharacterized HBD of IGF2 contributes the greatest to the heparinbinding affinity of the IGF2/IGFBP2 complex.

The results from heparin affinity chromatography not only confirm the importance of the IGFBP2 HBDs, but also emphasize a pivotal role for the IGF2 HBD. Of the three, the HBD in IGF2 contributes to the greatest extent to the affinity of IGF2/IGFBP2 for heparin. Combined with the insights offered by homology modeling of the IGF2/IGFBP2 complex, we propose a model of binding in which the IGF2 HBD aligns with the IGFBP2 linker and C-terminal domain HBDs to form a larger GAGbinding surface. This is consistent with previous observations that GAG affinity of the complex is greater than that for either protein alone (Arai et al. 1996, Conover \& Khosla 2003, Beattie et al. 2008). One limitation is, however, that the homology model does not include the flexible IGFBP2 linker domain, thus the model can neither account for the location of the IGFBP linker nor imply the significance or influence on heparin affinity. The pivotal role of the IGF2 HBD in the IGF2/IGFBP2 complex could explain as to why IGFBP2 bound to IGF2 and not to IGF1 shows targeted GAG binding, as IGF1 lacks an equivalent HBD motif (Fig. 2; Conover \& Khosla 2003). In binding with IGFBP2, IGF2 creates a more favorable interaction between IGFBP2 linker-HBD and heparin. The structural model predicted the IGF2-binding sites in IGFBP2 to potentially conflict with the C-terminal domain HBD residues, and this was consistent with the heparin affinity measurements indicating that the IGFBP2 HBDs in the binary complex were partly masked by the IGF2. The differential contribution of IGFBP2 HBDs could indicate that free IGFBP2 binds to GAGs primarily via the C-terminal domain HBD, while the linker region and IGF2 HBDs govern the binding of the binary complex. Furthermore, the affinity of these interactions may very well be GAG specific, as the IGFBP2 linker and C-terminal domain HBDs differ both at the primary and tertiary structural levels, thus opening for the possibility of IGF2dependent and GAG-specific targeting to ECM.

The IGF1R-binding residues of IGF2 (Arg24, Phe26, Tyr27, and Val43) appear not to interfere with heparin binding, but are as mentioned somewhat buried in the model, similar to the structure of the IGF1/IGFBP4 and IGF1/IGFBP5 complexes (Zesławski et al. 2001, Sitar et al. 2006). For IGFBP3 and IGFBP5, where the free IGFBP has a higher affinity for GAGs than the IGF/IGFBP complex the decrease in IGF affinity upon GAG binding would be a plausible mechanism for IGF activation in the ECM. In the case of IGF2/IGFBP2, however, where the complex has been shown to be equally good in stimulating osteoblasts grown on ECM as the free IGF2 (Conover \& Khosla 2003), release of IGF2 upon GAG binding seems implausible, as the complex demonstrates a higher GAG affinity than the free IGFBP2. The presented IGF2/IGFBP2 model may give us an alternative mechanism for explaining the high IGF activity of the complex. In this model, GAG binding induces a conformational change in the IGF2/IGFBP2 complex, exposing the partially buried IGF1R-binding residues of IGF2. Thus, the IGF2/IGFBP2 complex is targeted to cell surface by cell surface GAG binding, and a ternary complex of IGF2, IGFBP2, and GAGs can activate nearby IGF1R.

The pivotal role of the IGF2 HBD and its central position in the suggested IGF2/IGFBP2 combined heparin binding surface would support the latter interpretation, as would the decreased heparin-binding affinity of the free IGFBP2 compared to the IGF2/IGFBP2 complex. Finally, this mode of interaction would also leave IGF2 protected from IGF2R inactivation during the signaling event.

A recent study by Kuang et al. (2007) has suggested that heparin interacts with IGFBP2 and IGF1 to form larger complexes rather than leading to dissociation of the IGF1/IGFBP2 complex.

The proposed structural model suggests that IGF2/IGFBP2 GAG binding would further bury the adjacent IGF2 residues involved in IGF2R binding, indicating that IGF2/IGFBP2 GAG binding potentially plays a role in protecting IGF2 from clearance by IGF2Rmediated endocytosis (Bayes-Genis et al. 2000, Williams et al. 2007).

Published by Bioscientifica Ltd. 
While the heparin affinity column method inherently focuses on heparin, it should be noted that this polysaccharide is only one representative of the extremely variable GAGs. Heparin also has a very high negative charge density, and less sulfonated GAGs would elute at a lower $\kappa_{\mathrm{r}}$. The binding surface will accommodate similar sulfonated polysaccharides in accordance with the potential regulatory role of ECM GAG composition. In support of this view, our investigation of the IGF2/IGFBP2 heparin affinity dependence on the $\mathrm{pH}$ demonstrated that adding or removing a few charges by changing the protonation state of His residues can significantly alter the GAG affinity. These results were in excellent agreement with a recent study by Kuang et al. (2006) that also, using nuclear magnetic resonance (NMR)-followed sucrose octasulfate titration, identifies $\mathrm{pH}$-dependent protonation states of the IGFBP2 C-terminal domain HBD His residues. Hence, the $\mathrm{pH}$ of tissue ECM is a possible regulatory parameter of GAG affinity. Furthermore, cell type-specific GAGs show great structural variability and may differ in response to IGFBP2. Interestingly, Shen et al. has recently demonstrated an IGF1independent GAG-binding activity for the linker-HBD in vascular smooth muscle cells. In this study, IGFBP2 was shown to bind to the proteoglycan receptor protein tyrosine phosphatase $\beta$ via the linker-HBD independent of IGF1 binding. This binding in turn enhanced IGF1stimulated vascular smooth muscle cell migration and proliferation (Shen et al. 2012).

Our results challenge some of the conclusions drawn from previous studies utilizing isolated IGFBP2 domains, and in doing so emphasize the importance of analyzing protein-protein and protein-GAG interactions in an integrated manner. Further studies will be needed to delineate the underlying molecular mechanism of the suggested IGF1R activation by the IGF2/IGFBP2/GAG ternary complex. The heparin-binding mechanism delineated in this study may lay the foundation for therapeutic intervention of IGFBP2-associated diseases, such as certain types of cancer, using heparin or heparin analogs for prevention of IGFBP2-mediated IGFR1 activity. Knowledge of the molecular details of GAG binding may also spur development of potential new anabolic therapies targeting bone ECM.

Supplementary data

This is linked to the online version of the paper at http://dx.doi.org/10.1530/ JME-13-0184.

http://jme.endocrinology-journals.org DOI: 10.1530/JME-13-0184

C) 2014 Society for Endocrinology Printed in Great Britain
Declaration of interest

The authors declare that there is no conflict of interest that could be perceived as prejudicing the impartiality of the research reported.

\section{Funding}

This research did not receive any specific grant from any funding agency in the public, commercial or not-for-profit sector.

Author contribution statement

C A C and M T O conceived and designed the study. J L and M T S performed experiments. J L, M T S, and M T O analyzed data. All authors wrote the manuscript.

\section{Acknowledgements}

The authors thank Heidi N Danielsen, Freja Aasted, Eva K Andresen, Susan $\mathrm{H}$ Jensen, Mai-Britt Brøndum, and Hanne K Nielsen for their help with the experimental procedures.

\section{References}

Arai T, Busby W \& Clemmons DR 1996 Binding of insulin-like growth factor (IGF) I or II to IGF-binding protein-2 enables it to bind to heparin and extracellular matrix. Endocrinology 137 4571-4575.

Arnett T 2003 Regulation of bone cell function by acid-base balance. Proceedings of the Nutrition Society 62 511-520. (doi:10.1079/ PNS2003268)

Bach LA, Headey SJ \& Norton RS 2005 IGF-binding proteins - the pieces are falling into place. Trends in Endocrinology and Metabolism 16 228-234. (doi:10.1016/j.tem.2005.05.005)

Bayes-Genis A, Conover CA \& Schwartz RS 2000 The insulin-like growth factor axis: a review of atherosclerosis and restenosis. Circulation Research 86 125-130. (doi:10.1161/01.RES.86.2.125)

Beattie J, Phillips K, Shand JH, Szymanowska M, Flint DJ \& Allan GJ 2008 Molecular interactions in the insulin-like growth factor (IGF) axis: a surface plasmon resonance (SPR) based biosensor study. Molecular and Cellular Biochemistry 307 221-236. (doi:10.1007/ s11010-007-9601-8)

Brown J, Delaine C, Zaccheo OJ, Siebold C, Gilbert RJ, van Boxel G, Denley A, Wallace JC, Hassan AB, Forbes BE et al. 2008 Structure and functional analysis of the IGF-II/IGF2R interaction. EMBO Journal 27 265-276. (doi:10.1038/sj.emboj.7601938)

Butler AA, Yakar S, Gewolb IH, Karas M, Okubo Y \& LeRoith D 1998 Insulin-like growth factor-I receptor signal transduction: at the interface between physiology and cell biology. Comparative Biochemistry and Physiology. Part B, Biochemistry \& Molecular Biology 121 19-26. (doi:10.1016/S0305-0491(98)10106-2)

Cardin AD \& Weintraub HJ 1989 Molecular modeling of proteinglycosaminoglycan interactions. Arteriosclerosis 9 21-32. (doi:10.1161/ 01.ATV.9.1.21)

Clemmons DR 1997 Insulin-like growth factor binding proteins and their role in controlling IGF actions. Cytokine \& Growth Factor Reviews $\mathbf{8}$ 45-62. (doi:10.1016/S1359-6101(96)00053-6)

Clemmons DR 2001 Use of mutagenesis to probe IGF-binding protein structure/function relationships. Endocrine Reviews 22 800-817. (doi:10.1210/edrv.22.6.0449)

Conover CA 1992 Potentiation of insulin-like growth factor (IGF) action by IGF-binding protein-3: studies of underlying mechanism. Endocrinology 130 3191-3199.

Published by Bioscientifica Ltc. 
Conover CA 2008 Insulin-like growth factor-binding proteins and bone metabolism. American Journal of Physiology. Endocrinology and Metabolism 294 E10-E14. (doi:10.1152/ajpendo.00648.2007)

Conover CA \& Khosla S 2003 Role of extracellular matrix in insulin-like growth factor (IGF) binding protein-2 regulation of IGF-II action in normal human osteoblasts. Growth Hormone \& IGF Research 13 328-335. (doi:10.1016/S1096-6374(03)00092-3)

Denley A, Cosgrove LJ, Booker GW, Wallace JC \& Forbes BE 2005 Molecular interactions of the IGF system. Cytokine \& Growth Factor Reviews 16 421-439. (doi:10.1016/j.cytogfr.2005.04.004)

Eisenberg D, Lüthy R \& BowieJU 1997 VERIFY3D: assessment of protein models with three-dimensional profiles. Methods in Enzymology 277 396-404

Eswar N, Marti-Renom MA, Webb B, Madhusudhan MS, Eramian D, Shen M, Pieper U \& Sali A 2006 Comparative protein structure modeling with MODELLER. Current Protocols in Bioinformatics 2 unit 2.9. (doi:10.1002/0471140864.ps0209s50)

Firth SM \& Baxter RC 2002 Cellular actions of the insulin-like growth factor binding proteins. Endocrine Reviews 23 824-854. (doi:10.1210/ er.2001-0033)

Forbes BE, McCarthy P \& Norton RS 2012 Insulin-like growth factor binding proteins: a structural perspective. Frontiers in Endocrinology 3 38. (doi:10.3389/fendo.2012.00038)

Frasca F, Pandini G, Scalia P, Sciacca L, Mineo R, Costantino A, Goldfine ID, Belfiore A \& Vigneri R 1999 Insulin receptor isoform A, a newly recognized, high-affinity insulin-like growth factor II receptor in fetal and cancer cells. Molecular and Cellular Biology 19 3278-3288.

Galea CA, Mobli M, McNeil KA, Mulhern TD, Wallace JC, King GF, Forbes BE \& Norton RS 2012 Insulin-like growth factor binding protein-2: NMR analysis and structural characterization of the N-terminal domain. Biochimie 94 608-616. (doi:10.1016/j.biochi. 2011.09.012)

Hodgkinson SC, Napier JR, Spencer GS \& Bass JJ 1994 Glycosaminoglycan binding characteristics of the insulin-like growth factor-binding proteins. Journal of Molecular Endocrinology 13 105-112. (doi:10.1677/ jme.0.0130105)

Jones JI, Gockerman A, Busby WH, Camacho-Hubner C \& Clemmons DR 1993 Extracellular matrix contains insulin-like growth factor binding protein-5: potentiation of the effects of IGF-I. Journal of Cell Biology $\mathbf{1 2 1}$ 679-687. (doi:10.1083/jcb.121.3.679)

Kalus W, Zweckstetter M, Renner C, Sanchez Y, Georgescu J, Grol M, Demuth D, Schumacher R, Dony C, Lang K et al. 1998 Structure of the IGF-binding domain of the insulin-like growth factor-binding protein5 (IGFBP-5): implications for IGF and IGF-I receptor interactions. EMBO Journal 17 6558-6572. (doi:10.1093/emboj/17.22.6558)

Kapust RB, Tözsér J, Fox JD, Anderson DE, Cherry S, Copeland TD \& Waugh DS 2001 Tobacco etch virus protease: mechanism of autolysis and rational design of stable mutants with wild-type catalytic proficiency. Protein Engineering 14 993-1000. (doi:10.1093/protein/14. 12.993)

Khosla S, Hassoun AA, Baker BK, Liu F, Zein NN, Whyte MP, Reasner CA, Nippoldt TB, Tiegs RD, Hintz RL et al. 1998 Insulin-like growth factor system abnormalities in hepatitis C-associated osteosclerosis. Potential insights into increasing bone mass in adults. Journal of Clinical Investigation 101 2165-2173. (doi:10.1172/JCI1111)
Kuang Z, Yao S, Keizer DW, Wang CC, Bach LA, Forbes BE, Wallace JC \& Norton RS 2006 Structure, dynamics and heparin binding of the C-terminal domain of insulin-like growth factor-binding protein-2 (IGFBP-2). Journal of Molecular Biology 364 690-704. (doi:10.1016/ j.jmb.2006.09.006)

Kuang Z, Yao S, McNeil KA, Thompson JA, Bach LA, Forbes BE, Wallace JC \& Norton RS 2007 Cooperativity of the N- and C-terminal domains of insulin-like growth factor (IGF) binding protein 2 in IGF binding. Biochemistry 46 13720-13732. (doi:10.1021/bi701251d)

Mark S, Kübler B, Höning S, Oesterreicher S, John H, Braulke T, Forssmann W-G \& Ständker L 2005 Diversity of human insulin-like growth factor (IGF) binding protein-2 fragments in plasma: primary structure, IGF-binding properties, and disulfide bonding pattern. Biochemistry 44 3644-3652. (doi:10.1021/bi0478401)

Nili M, Mukherjee A, Shinde U, David L \& Rotwein P 2012 Defining the disulfide bonds of insulin-like growth factor-binding protein- 5 by tandem mass spectrometry with electron transfer dissociation and collision-induced dissociation. Journal of Biological Chemistry $\mathbf{2 8 7}$ 1510-1519. (doi:10.1074/jbc.M111.285528)

Russo VC, Schütt BS, Andaloro E, Ymer SI, Hoeflich A, Ranke MB, Bach LA \& Werther GA 2005 Insulin-like growth factor binding protein-2 binding to extracellular matrix plays a critical role in neuroblastoma cell proliferation, migration, and invasion. Endocrinology 146 4445-4455. (doi:10.1210/en.2005-0467)

Shen X, Xi G, Maile LA, Wai C, Rosen CJ \& Clemmons DR 2012 Insulin-like growth factor (IGF) binding protein 2 functions coordinately with receptor protein tyrosine phosphatase $\beta$ and the IGF-I receptor to regulate IGF-I-stimulated signaling. Molecular and Cellular Biology 32 4116-4130. (doi:10.1128/MCB.01011-12)

Sitar T, Popowicz GM, Siwanowicz I, Huber R \& Holak TA 2006 Structural basis for the inhibition of insulin-like growth factors by insulin-like growth factor-binding proteins. PNAS 103 13028-13033. (doi:10.1073/ pnas.0605652103)

Siwanowicz I, Popowicz GM, Wisniewska M, Huber R, Kuenkele K-P, Lang K, Engh RA \& Holak TA 2005 Structural basis for the regulation of insulinlike growth factors by IGF binding proteins. Structure 13 155-167. (doi:10.1016/j.str.2004.11.009)

Smith MC, Cook JA, Furman TC \& Occolowitz JL 1989 Structure and activity dependence of recombinant human insulin-like growth factor II on disulfide bond pairing. Journal of Biological Chemistry 264 9314-9321.

Torres AM, Forbes BE, Aplin SE, Wallace JC, Francis GL \& Norton RS 1995 Solution structure of human insulin-like growth factor II. Relationship to receptor and binding protein interactions. Journal of Molecular Biology 248 385-401.

Williams C, Rezgui D, Prince SN, Zaccheo OJ, Foulstone EJ, Forbes BE, Norton RS, Crosby J, Hassan AB \& Crump MP 2007 Structural insights into the interaction of insulin-like growth factor 2 with IGF2R domain 11. Structure 15 1065-1078. (doi:10.1016/j.str.2007.07.007)

Zesławski W, Beisel HG, Kamionka M, Kalus W, Engh RA, Huber R, Lang K \& Holak TA 2001 The interaction of insulin-like growth factor-I with the N-terminal domain of IGFBP-5. EMBO Journal $203638-3644$ (doi:10.1093/emboj/20.14.3638)

Received in final form 2 March 2014

Accepted 6 March 2014

Accepted Preprint published online 6 March 2014 http://jme.endocrinology-journals.org DOI: 10.1530/JME-13-0184
(C) 2014 Society for Endocrinology Printed in Great Britain
Published by Bioscientifica Ltd 